\title{
Load carrying capacity of the eccentric joint in the truss made of open cross-sections
}

\author{
Małgorzata Gordziej-Zagórowska ${ }^{1,{ }^{*}}$, and Elżbieta Urbańska-Galewska $^{1}$ \\ ${ }^{1}$ Gdańsk University of Technology, Faculty of Civil and Environmental Engineering, Narutowicza \\ 11/12, 80-233 Gdańsk, Poland
}

\begin{abstract}
The influence of eccentricity at intersections of truss members on the load carrying capacity of the truss joint is presented in the paper. The research truss elements were designed as cold-formed open cross section. Analytical calculations, numerical analysis and experimental research were conducted to reveal how the eccentricity affects the effort of material in the joint area. The results of analysis and investigations are compared and discussed. The main achievement of the tests carried out is statement that slender plane members of the compression chords are safe compared with the results of analytical calculations.
\end{abstract}

\section{Introduction}

Cold-formed steel members constitute a significant part of steel building structures. A widespread application of these elements in various types of steel constructions causes that new research problems are still defined. Both individual structural elements such as beams or columns [1-2] and parts of the structure, including lattice girders, are tested [3-6].

In practice, in truss girders joints eccentricities often occur for technological reasons, causing local bending and shear forces in the truss chords [7]. In the case of structures made of closed cross-sections, the influence of the eccentricities on the load capacity of truss joints has already been thoroughly tested [8], [9]. However, in the case of trusses made of open cross-sections, such knowledge has not been acquired yet. In order to check the loadcarrying capacity of a truss chord cross-section of a bending truss joint, the designer formerly had to use simplified dimensioning methods [10-12]. This led to uneconomical solutions.

The lack of knowledge about the work of eccentric truss joints made of open crosssections was a direct reason for the presented research. The purpose of these studies and analysis was to check the extent the brace members stiffening the walls of the hat-section chord, as well as how it affects the load capacity of the joint.

\footnotetext{
*Corresponding author: malgor@pg.edu.pl
} 


\section{Scope of the work}

In order to study the above mentioned problem, analytical and numerical calculations as well as experimental research of the truss segment made of cold-formed open cross-section profiles were carried out. The chords were designed from the hat-section H 39/117/106/117/39x2, and the brace members of channel-section $C 17 / 75 / 100 / 75 / 17 \times 2$ (Fig. 1b, c). The assumed sections were made of galvanized steel S350GD with zinc surface Z275MA. The geometry of the research model used for testing is shown in Figure 1. The joint with the eccentricity of $\mathrm{e}=103.92 \mathrm{~mm}$ located in the compressed chord was taken for the analysis, because only the walls of the compression elements may lose local stability.

a)

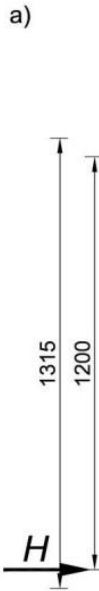

b)

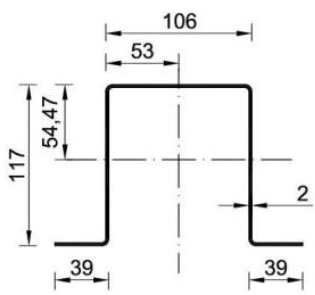

c)

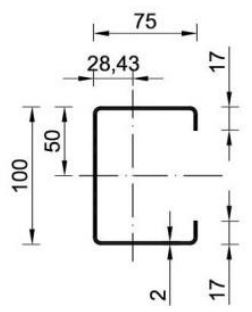

Fig. 1. a) research model; dimensions of profiles used in experimental research for: b) chords, c) brace members.

The research model was loaded with two concentrated forces $H$ and $P$. The force $H$ caused the compression of the bottom chord. The force $P$ caused local bending of the bottom chord in the joint area through the natural forces distribution in the eccentric joint.

In addition, the scope of analytical and numerical calculations has been extended by wall thickness values equal to: $1 \mathrm{~mm}, 1.5 \mathrm{~mm}$ and $4 \mathrm{~mm}$. A summary of performed types of analyses is presented in Table 1 .

Due to the use of the same model geometry as well as the load history in analytical and numerical analyses, it was possible to compare the results of calculations.

Table 1. Types of carried out analyses for the eccentricity e $=103.92 \mathrm{~mm}$.

\begin{tabular}{|c|c|c|c|c|}
\hline \multicolumn{2}{|c|}{} & analytical & experimental & numerical \\
\hline \multirow{4}{*}{$\begin{array}{c}\text { Wall thickness } \\
\text { (C-section and } \\
\text { hat-section) }\end{array}$} & $1.0 \mathrm{~mm}$ & $\mathrm{x}$ & & $\mathrm{x}$ \\
\cline { 2 - 5 } & $1.5 \mathrm{~mm}$ & $\mathrm{x}$ & & $\mathrm{x}$ \\
\cline { 2 - 5 } & $2.0 \mathrm{~mm}$ & $\mathrm{x}$ & $\mathrm{x}$ & $\mathrm{x}$ \\
\cline { 2 - 5 } & $4.0 \mathrm{~mm}$ & $\mathrm{x}$ & & $\mathrm{x}$ \\
\hline
\end{tabular}




\section{Analytical calculation}

In engineering practice, dimensioning of truss chords made of cold-formed open crosssections profiles, with positive eccentricities at intersections is carried out using the formulas specified in the standards [10]-[13]. In the considered case, the truss chord is divided into several members connected at the intersection points with the brace members, as shown in Figure 2.

a)

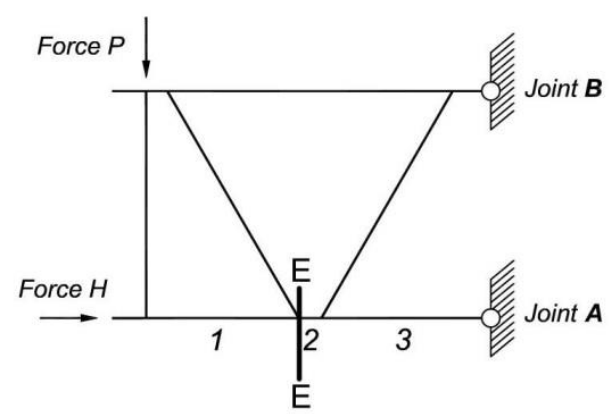

b)

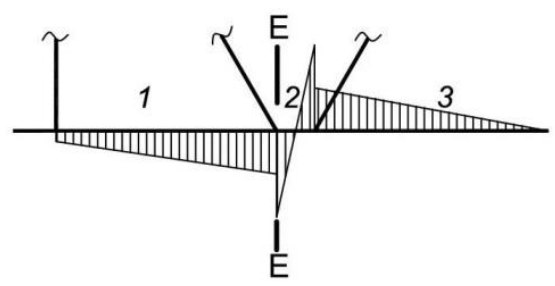

Fig. 2. a) Static scheme of the analysed truss along with the numbering of the analysed members of the compression chord, b) the graph of bending moments on the compression chord.

The values of internal forces can be determined in each chord member, for example by means of commercial computer programs. In the analysed case due to the existing positive eccentricity, apart from normal forces, shear forces and bending moments in the member No. 2 occur. Considering the forces occurring in all the members of the compression chord (No. $1 \div 3$ ), the effort of material at the particular cross-sections was calculated based on the elastic verification in accordance with equation (1) [11].

$$
\frac{N_{E d}}{N_{c, R d}}+\frac{M_{y, E d}+\Delta M_{y, E d}}{M_{c y, R d, c o m}} \leq 1,0
$$

where:

$\begin{array}{ll}\mathrm{N}_{\mathrm{Ed}} & \text { compression force, } \\ \mathrm{M}_{\mathrm{y}, \mathrm{Ed}} & \text { bending moment (resulting from the eccentricity at the joint), } \\ \Delta \mathrm{M}_{\mathrm{y}, \mathrm{Ed}} & \begin{array}{l}\text { additional moment due to the movement of the centre of gravity of the } \\ \text { section (for class } 4 \text { ), }\end{array} \\ \mathrm{N}_{\mathrm{c}, \mathrm{Rd}} & \begin{array}{l}\text { design resistance of the compressed cross-section, } \\ \mathrm{M}_{\mathrm{cy}, \mathrm{Rd}, \mathrm{com}}\end{array} \quad \text { effective design resistance for bending. }\end{array}$

The effort of material at the cross-section of the bent and compressed member No. 2 (in the middle of the joint) is always greater than the material effort at members No. 1 and No. 3. This is related to the occurrence of shear forces and bending moments (consequence of the positive eccentricity). Therefore, it is logical that in the design situation exceeding of the joint resistance is a signal for the constructor to increase the cross-section of an entire chord or make strengthening covers in the joint area, as presented in [14].

Figure 3 shows a plot of the effort of material at the cross-section E-E (Fig. 1a) developed on the basis of calculation results (equation (1)) of joint with eccentricity $\mathrm{e}=103.92 \mathrm{~mm}$ for all analysed wall thicknesses: $1 \mathrm{~mm}, 1.5 \mathrm{~mm}, 2 \mathrm{~mm}$ and $4 \mathrm{~mm}$. According to the classification included in the standard [8], sections with wall thickness of $1 \mathrm{~mm}, 1.5 \mathrm{~mm}$ and $2 \mathrm{~mm}$ are class 4 sections and a $4 \mathrm{~mm}$ - class 2 section. Figure 3 shows a significant decrease in the joint resistance of class 4 sections in terms of class 2 section. 


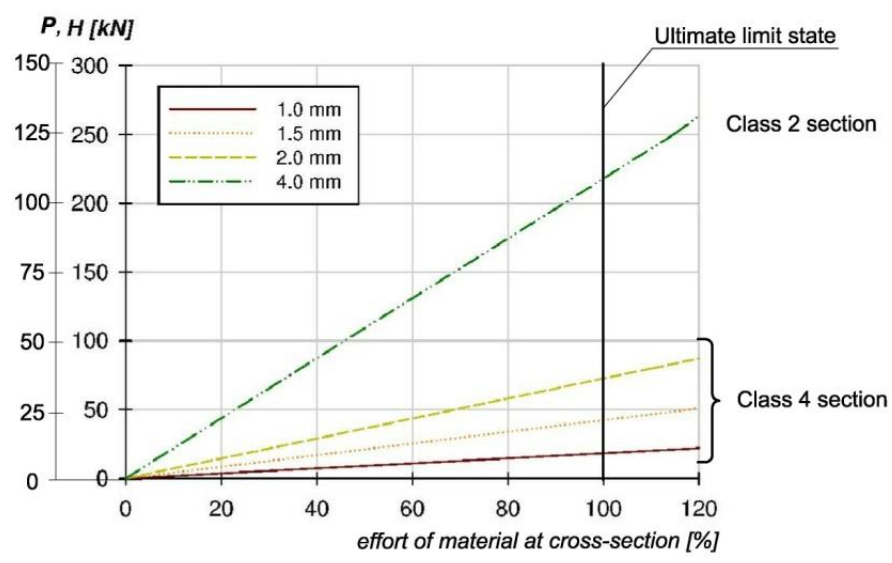

Fig. 3. Diagram of the relationship of the effort of material at cross-section E-E in dependence on the applied load, determined on the basis of analytical, elastic calculations.

\section{Experimental research}

Experimental research of the load capacity of a truss joint with the eccentricity $\mathrm{e}=103.92 \mathrm{~mm}$ was conducted on truss girder models in 1:1 scale (Fig. 1). The destructive tests of 5 similar truss models were performed.

A detailed description of the course of the experimental tests is presented in [7].

The purpose of the test was to determine the deformation forms and strains of the hatsection in the joint area, thus the investigations were carried out to register the strains in several measurement cross-sections, including the place of maximum bending moment (EE section - Fig. 1a).

During the destructive tests local instability of hat-section in the E-E cross-section was observed in the all research models.

The origin of local instability of the walls of the hat-section in the E-E cross-section was defined as the critical state of the cross-section. When the critical load had been reached, the structure worked at its postcritical state, until it reached the limit state. In the analysed joint area, the onset of yield stress of the hat-section corners was identified as the ultimate limit state (see Figure 4).

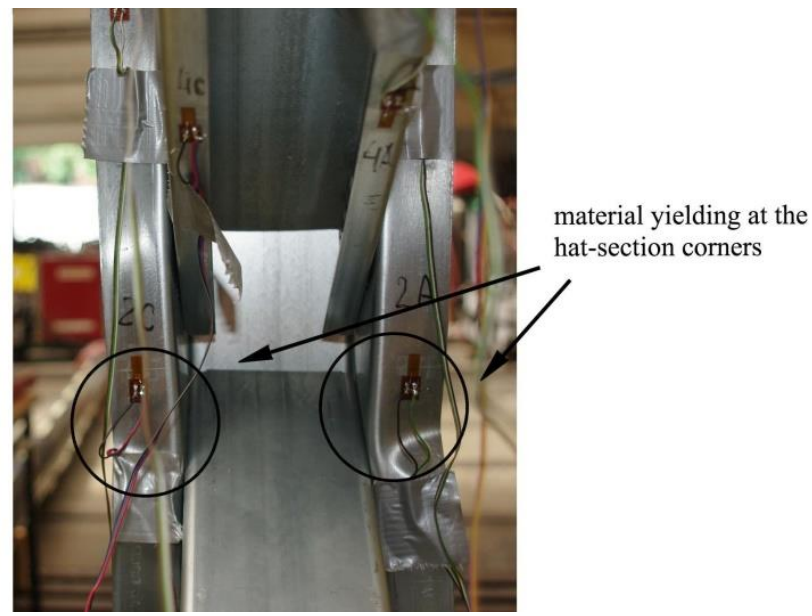

Fig. 4. Material yielding at the hat-section corners in the analysed joint area. 
Based on the destructive tests of the five research models (M2 - M6), the critical load values were obtained as a combination of forces: $P$ and the corresponding force $H$, summarized in table 2. The standard deviation of the critical load was calculated for models M2 to M5. The results obtained from the M6 model were neglected due to significant differences in the recorded strains at the measurement cross-sections. The M1 model was used to test the research station.

Table 2. Combination of forces $P$ i $H_{c o r}$ corresponding to the critical load of the hat-section.

\begin{tabular}{|c|c|c|c|c|c|c|}
\hline $\begin{array}{c}\text { Research } \\
\text { model } \\
\text { number }\end{array}$ & $\begin{array}{l}\text { Force } \\
P[\mathrm{kN}]\end{array}$ & $\begin{array}{l}\text { Average } \\
P_{a v}[\mathrm{kN}]\end{array}$ & $\begin{array}{c}\text { Standard } \\
\text { deviation } \\
S P[-] \\
\end{array}$ & $\begin{array}{c}\text { Force } \\
\text { Hodp }_{\text {od }}[\mathrm{kN}]\end{array}$ & $\begin{array}{c}\text { Average } \\
\boldsymbol{H}_{c o r, a v}[\mathbf{k N}]\end{array}$ & $\begin{array}{c}\text { Standard } \\
\text { deviation } \\
s_{H}[-] \\
\end{array}$ \\
\hline M2 & 8.5 & \multirow{4}{*}{6.98} & \multirow{4}{*}{1.5} & 96 & \multirow{4}{*}{91.75} & \multirow{4}{*}{4.4} \\
\hline M3 & 7.7 & & & 89 & & \\
\hline M4 & 5.0 & & & 95 & & \\
\hline M5 & 6.7 & & & 87 & & \\
\hline M6 & 5.0 & - & - & 106 & - & - \\
\hline
\end{tabular}

The aim of the experimental research, apart from obtaining the information about the work of the truss segment with the positive eccentricity in the joint, was also the validation of the computational model. Therefore, the obtained results in the form of a register of strains and displacements of the model as well as deformations of the joint constituted the basis for the validation of the numerical model.

\section{Numerical analysis}

The numerical model of the truss segment was made in the MSC Marc program using the finite element method - FEM. Figure 5 shows the geometry of the numerical model. Numerical research has been divided into two stages:

- Stage I - validation of the calculation model,

- Stage II - numerical analysis.

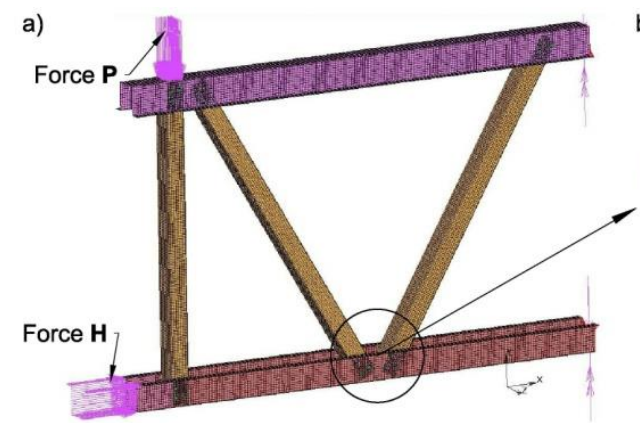

b)

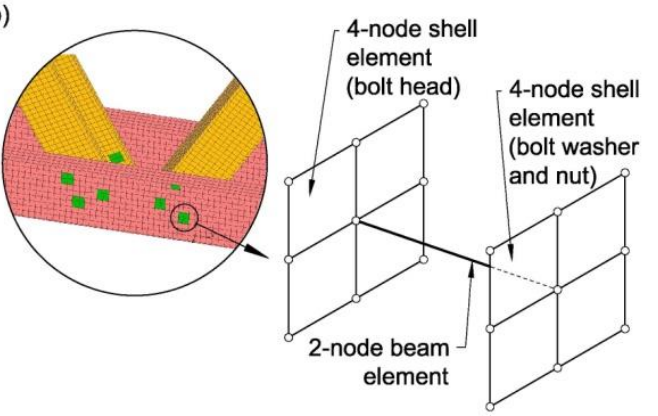

Fig. 5. Numerical model: a) truss structure, b) detail of the bolted connection [15].

The validation of the numerical model was carried out to check out if whether the numerical model correctly describes the real behaviour of the structure [15]. It was possible because of the data obtained from experimental research. When the validation of the computational model was completed, appropriate numerical analyses were started. In these 
analyses, the wall thickness values of the research models members were taken separately, similarly to the case of analytical calculations (point 3 ).

In order to numerically model the cold-formed members the 4-node shell elements were applied, the 2-node beam elements were applied for the bolt model. The developed bolted connection model consisted of the 2-node beam element imitating the bolt shank and two stiff areas consisted of four 4-node elements, imitating the bolt head on one side (on the web of the hat-section) and a washer with a nut on the other (as a part of the channel section flange). The rigid areas were modelled by thickened four 4-node shell elements (Figure 5b). The bolted connection models were taken at the locations of real bolts in order to obtain the point connection of the channel brace members and hat-section chord.

The research model was loaded with two forces: the force $H$ and the force $P$ in a ratio of $2: 1$, similarly as in the experimental research.

Figure $6 \mathrm{a}-\mathrm{d}$, presents the deformations of the research model corresponding to the state of failure for all considered variants of models. Two cross-sections were analysed:

- E-E located at the place of maximum bending moment of the analysed joint,

- M-M defined as the cross-section in which the greatest deformations occurred (place of destruction - Figure 6 a-d).

a)

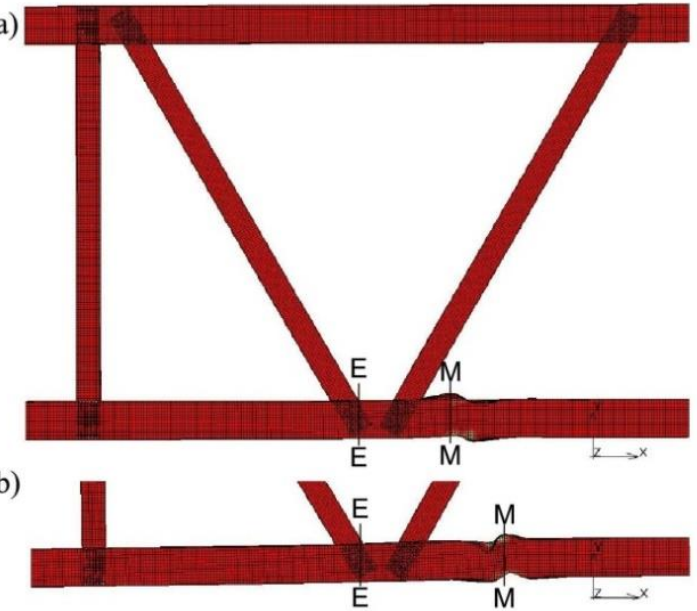

e)

c)
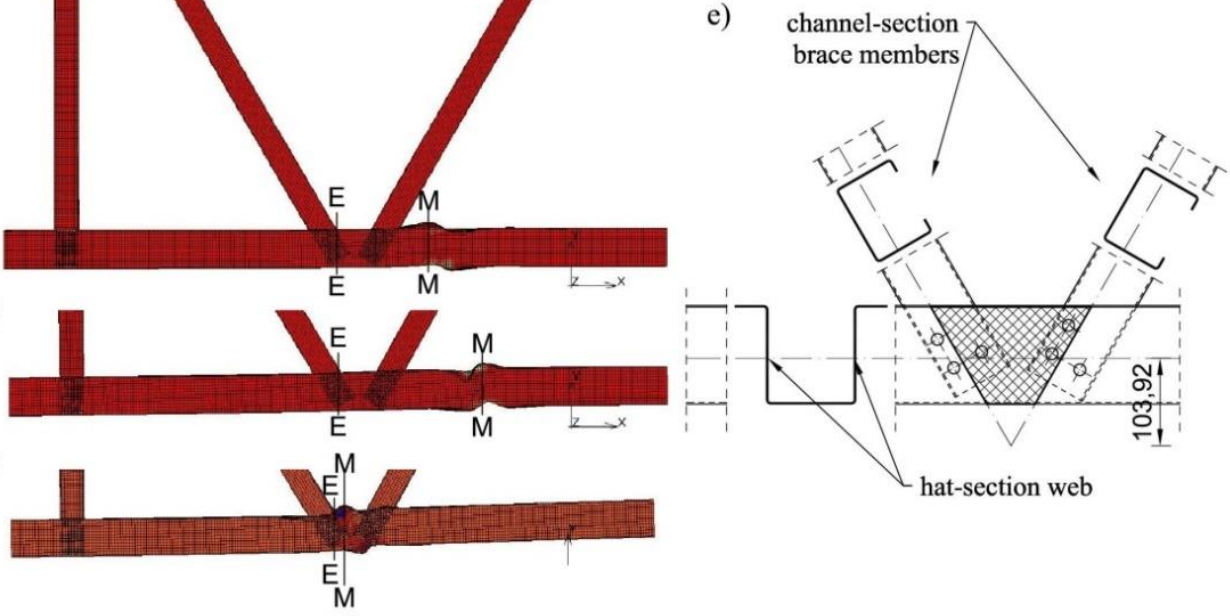

d)

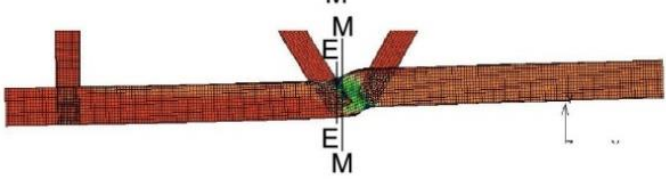

Fig. 6. Position of the M-M cross-section at research models with the wall thicknesses: a) $1 \mathrm{~mm}, \mathrm{~b}$ ) $1.5 \mathrm{~m}$, c) $2.0 \mathrm{~mm}$, d) of $4.0 \mathrm{~mm}$, e) shape of stiffened web zones of the hat-section chord.

Based on numerical analyses, the critical and ultimate load values summarized in Table 3 were obtained. Critical load was obtained on the basis of linear elastic bifurcation analysis (LBA), the limit load on the basis of geometric and material nonlinear analysis (GMNA).

In the case of profiles with a wall thickness of $1 \mathrm{~mm}$ and $1.5 \mathrm{~mm}$, an increase in the critical load value due to the ultimate load value is observable. In the case of profiles with a wall thickness of $4 \mathrm{~mm}$, the value of critical load corresponds to the global buckling form 
and is larger than the ultimate load, what is consistent with the limit load theory of compressed members. However, in the case of a $2 \mathrm{~mm}$ thick section, although it meets the standard [10] class 4 criteria and according to this classification should be subjected to the theory of postcritical plate resistance, however the critical load is greater than the ultimate load. Therefore, at this stage of the research it was concluded that the results for the $2 \mathrm{~mm}$ thick section are not unambiguous. In the future, a more detailed numerical model of the node is planned.

Table 3. Comparison of critical and ultimate load values for all analysed variants.

\begin{tabular}{|c|c|c|c|c|c|c|}
\hline & \multicolumn{2}{|c|}{$\begin{array}{c}\text { Critical load } \\
\text { (based on the LBA analysis) }\end{array}$} & \multicolumn{2}{c|}{$\begin{array}{c}\text { Ultimate Load } \\
\text { (based on the GMNA analysis) }\end{array}$} & \multicolumn{2}{c|}{ Load increase } \\
\hline $\begin{array}{c}\text { Wall } \\
\text { thicknesses }\end{array}$ & $\boldsymbol{P}_{\boldsymbol{c r}}[\mathbf{k N}]$ & $\boldsymbol{H}_{\boldsymbol{c r}}[\mathbf{k N}]$ & $\boldsymbol{P}_{\boldsymbol{u}}[\mathbf{k N}]$ & $\boldsymbol{H}_{\boldsymbol{u}}[\mathbf{k N}]$ & $\boldsymbol{P}[\%]$ & $\boldsymbol{H}[\%]$ \\
\hline $\mathbf{1 . 0} \mathbf{~ m m}$ & 7.62 & 15.22 & 16.2 & 32.33 & 112.6 & 112.4 \\
\hline $\mathbf{1 . 5} \mathbf{~ m m}$ & 24.87 & 49.69 & 32.69 & 65.23 & 31.5 & 31.3 \\
\hline $\mathbf{2 . 0} \mathbf{~ m m}$ & 58.14 & 116.17 & 55.62 & 111.23 & -4.3 & -4.3 \\
\hline $\mathbf{4 . 0} \mathbf{~ m m}$ & 306.38 & 612.60 & 133.13 & 265.71 & -56.5 & -56.6 \\
\hline
\end{tabular}

\section{Comparison of results}

Comparing the analytical calculations with the results of numerical analysis, it can be observed that the value of the ultimate load determined numerically $\left(X_{n u m}\right)$ is higher than the value of the truss design load $\left(X_{a n}\right)$ (Table 4$)$ in all variants. It should be noted that at this stage of research, imperfections have not been yet included in numerical analysis, however, affecting on the increase of the result values.

Table 4. Comparison of limit load values determined on the basis of analytical calculations and numerical analysis.

\begin{tabular}{|c|c|c|c|c|c|c|}
\hline \multirow[b]{2}{*}{$\begin{array}{c}\text { Wall } \\
\text { thicknesses }\end{array}$} & \multicolumn{2}{|c|}{$\begin{array}{c}\text { analytical calculations } \\
X_{a n}\end{array}$} & \multicolumn{2}{|c|}{$\begin{array}{c}\text { numerical analysis } \\
X_{\text {num }}\end{array}$} & \multicolumn{2}{|c|}{$\begin{array}{l}\text { Relative ratio } \\
\left(X_{n u m}-X_{a n}\right) / X_{a n}\end{array}$} \\
\hline & $P_{u}[k N]$ & $\mathbf{H}_{\mathrm{u}}[\mathrm{kN}]$ & $P_{u}[k N]$ & $\mathrm{H}_{\mathrm{u}}[\mathrm{kN}]$ & $\mathbf{P}[\%]$ & H [\%] \\
\hline $1.0 \mathrm{~mm}$ & 9.1 & 18.3 & 16.2 & 32.33 & 78 & 78 \\
\hline $1.5 \mathrm{~mm}$ & 21.4 & 42.7 & 32.69 & 65.23 & 53 & 53 \\
\hline $2.0 \mathrm{~mm}$ & 37.0 & 74.0 & 55.62 & 111.23 & 50 & 50 \\
\hline $4.0 \mathrm{~mm}$ & 112.2 & 224.5 & 133.13 & 265.71 & 19 & 19 \\
\hline
\end{tabular}

The increase of ultimate resistance determined numerically in relation to the values obtained by analytical methods is particularly large at class 4 sections. It confirms their high imperfection sensitivity.

The most important result of the numerical analysis was that in the cases of $1 \mathrm{~mm}$ and $1,5 \mathrm{~mm}$ walls thickness, considering local stiffening of the hat-section webs through the channel-section walls (Fig. 6 e), the failure (M-M section - Figure 6 a-d) of the compression chord occurs beyond the analysed joint, while the approximate analytical calculations show that the cross-section at the joint is a critical one (regardless of the thickness of the profile walls). 


\section{Conclusions}

The analysis of the results of the tested truss segment with the eccentricity $\mathrm{e}=103.92 \mathrm{~mm}$ in the joint, obtained on the basis of analytical, experimental and numerical tests of various wall thicknesses allowed to state that following cases occur due to a chord web (plate element) slenderness:

$-\lambda>70$ : the channel-sections brace members stiffen the web walls of the hat-section chord in the joint area.

$-\lambda<70$ : no influence of local stiffeners on the stiffness of the web walls of the hatsection was observed.

In order to confirm the conclusions, further analyses are expected for other eccentricity values in the joint. It will also be necessary to carry out analyses including imperfections.

\section{References}

1. D. Dubina, Foreword, Thin-Walled Struct., 42, 2, 149-152, (2004)

2. P. Deniziak, K. Winkelmann, Shell Struct. Theory Apl., 4, 533-536, (2018)

3. J. Jankowska-Sandberg, J. Kołodziej, Eng. Struct., 46, 165-172, (2013)

4. D. Visy, S. Adany, A. L. Joo, Eighth Int. Conf. Adv. Steel Struct.,1-18, (2015)

5. J. L. Dawe, Y. Liu, J. Y. Li, J. Constr. Steel Res., 66, 4, 556-565, (2010)

6. M. Krajewski, P. Iwicki, Recent Prog. Steel Compos. Struct. Proc. 13th Int. Conf. Met. Struct. Zielona Góra Pol., 417-424, (2016)

7. M. Gordziej-Zagórowska, E. Urbańska-Galewska, P. Deniziak, Ł. Pyrzowski, Civ. Environ. Eng. Rep., 25, 2, 107-123, (2017)

8. J. Bródka, M. Broniewicz, Konstrukcje stalowe z rur. (Arkady, Warszawa, 2001).

9. J. Bródka, M. Broniewicz, Konstrukcje stalowe z kształtowników zamkniętych, t. I. (Polskie Wydawnictwo Techniczne, Rzeszów, 2016)

10. EN 1993-1-1, Eurocode 3: Design of steel structures - Part 1-1: General rules and rules for buildings, Eur. Comm. Stand., (2005)

11. EN 1993-1-3, Eurocode 3: Design of steel structures - Part 1-3: General rules Supplementary rules for cold-formed members and sheeting, Eur. Comm. Stand., (2006)

12. EN 1993-1-8, Eurocode 3: Design of steel structures - Part 1-8: Design of joints, Eur. Comm. Stand., (2005)

13. EN 1993-1-5, Eurocode 3: Design of steel structures - Part 1-5: General rules - Plated structural elements, Eur. Comm. Stand., (2006)

14. M. Gordziej-Zagórowska, E. Urbańska-Galewska, Ł. Pyrzowski, P. Deniziak, A. Łukowicz, Recent Prog. Steel Compos. Struct. Proc. 13th Int. Conf. Met. Struct. Zielona Góra Pol., 425-432, (2016)

15. M. Gordziej-Zagórowska, E. Urbańska-Galewska, Ł. Pyrzowski, Shell Struct. Theory Apl., 4, 417-420, (2018) 